\title{
From free market to social policies? Mapping regulatory cooperation in education and health in MERCOSUR ${ }^{\mathrm{i}}$
}

\author{
Andrea C. Bianculli \\ Assistant Professor \\ Institut Barcelona d'Estudis Internacionals (IBEI) \\ abianculli@ibei.org
}

\begin{abstract}
Accepted for publication in Global Social Policy. Please cite as follows:
Bianculli, A. C. 2018. From free market to social policies? Mapping regulatory cooperation in education and health in MERCOSUR. Global Social Policy 18(3):249-266.

doi:10.1177/1468018118780085
\end{abstract}

\begin{abstract}
Regional cooperation has been an enduring feature of Latin American politics for more than half a century. With the turn of the century, regional organizations moved beyond traditional free trade issues to embrace cooperation in broader social policy areas. A recent and broad literature relates this change to the left turn in the region, especially in South America. Yet, in practice, relevant differences persist in terms of how social policy is regulated at the regional level. This paper looks precisely into this variation. In essence, it studies regulatory cooperation in the Common Market of the South (MERCOSUR), and thus offers a comparative assessment of the institutions and policy instruments devised in two social areas: education and health. Using an original dataset on the documents passed by MERCOSUR between 1991 and 2016, the findings provide evidence that the definition of the policy problem matters as this affects the institutional mechanisms and the policy instruments and strategies devised to address them. In this context, different policy problem definitions seem to account for two distinct emerging patterns of social regulatory cooperation in the Southern Cone.
\end{abstract}

\section{Keywords}

Education, health, Latin America, MERCOSUR, regional cooperation, social policy, and regulation 


\section{Introduction}

Regionalism spans the history of Latin America. Starting in the 1990s, new organizations were constructed and old ones reconstructed and reframed, as countries pursued a multitier strategy of trade liberalization. With the turn of the century, new regional initiatives moved beyond traditional free trade issues to embrace cooperation in broader economic, political and social policy areas. Regionalism was thus increasingly defined by the need to lessen dependence and promote development while a complex mosaic of regional organizations including complementary and competing ones with overlapping memberships - took shape (Bianculli, 2016a).

The introduction of new regional political and regulatory initiatives in the social policy domain symbolizes one of the latest changes in the regional cooperation landscape in Latin America, but also beyond. These empirical developments have ushered in new analyses that paint an increasingly nuanced picture of the manner in which regional cooperation proceeds as new arrangements, which range from health and education to employment and migration, take place (see interalia Bianculli and Ribeiro Hoffman (2016b), Riggirozzi and Yeates (2015)).

This paper seeks to build on this literature. Much of these studies have linked the rise in the salience of social policy and development at the regional tier of governance to the political shift to the Left in Latin America, and especially in South America in the early 2000s. Additionally, most of these contributions, while acknowledging the relevance of the regional level for social policy, have been more strongly focused on single cases of either regional organizations or specific policy sectors. Less emphasis has been given to how regional regulation across social policy areas works. These emerging regional regulations and arrangements are certainly critical and offer a rich vein for both social policy regionalism (Bianculli and Ribeiro Hoffmann, 2016b) and comparative regionalism research. Among other things, cooperation beyond trade is not strictly an exclusive by-product of the political shift to the left, and such initiatives also display significant diversity in terms of the policy problems being addressed and the institutional mechanisms and policy instruments implemented.

This paper attempts to fill in this gap by exploring how regional policy problems are defined (Peters, 2005; Peters, 2015a; Hoornbeek and Peters, 2017). In so doing, it offers some initial but important empirical insights on how problem definition affects the institutions and instruments devised to implement regional policies and regulations. 
My focus is on the Common Market of the South (MERCOSUR), which provides an interesting case to analyse the process of social policy expansion at the regional level. First, the bloc was established in the 1990s, when new regionalism pervaded the ways in which regions and regional institutions sought to effectively insert in an increasingly globalized world. Yet, despite its trade focus, already in its initial years MERCOSUR made some steps towards the regulation of education and health. Secondly, as it is the case of regional organizations in Latin America, decision-making remains highly intergovernmental and states are key actors in regional processes.

Based on these insights, this paper investigates and comparatively assesses the policy problems and the resulting institutions and policy instruments adopted since the creation of MERCOSUR across two social policy sub-fields: education and health. In all, one of the main findings is that even if education and health are part of the so-called social agenda or social dimension of regionalism, they evidence interesting differences when it comes to the nature of the policy problems these intend to address, thus leading to different institutional mechanisms and policy strategies.

The paper is organized in four parts. After discussing the current state of the literature, I outline the theoretical and methodological framework for comparatively studying social policy fields. The profiles of education and health regionalism in MERCOSUR follow, whereas the final section offers a discussion of the main findings and concluding thoughts on the implications of foregoing for social policy regionalism, whereby social policy offers a case through which to examine, assess, and compare regionalism.

\section{What do we know about regional cooperation and social policies and regulations?}

Regional organizations are certainly changing the landscape of social policy as they move away from traditional trade and market-based agendas to embrace and promote cooperation in wider social policy fields. These developments present challenges for policy makers and theorists alike.

The complexity of social policy governance has triggered new analytical frameworks that depart from prevailing (domestic) comparative political approaches (Surender and Walker, 2013; Kennett, 2013). Moving away from this 'methodological nationalism' (Yeates, 2014a), studies on the provision of and regulation of public goods beyond the state have more 
strongly looked into the global level (Bianculli and Ribeiro Hoffmann, 2016b). Focus has been on the international governance of social policy, including the role of international organizations, global networks and partnerships (Deacon, 2007). Studies have thus looked into the United Nations (UN) system organizations both of a global and regional scope, i.e. Economic and Social Council (ECOSOC), the United Nations Development Programme (UNDP), the World Health Organization (WHO), the International Labour Organization (ILO), the UN Economic Commission for Latin America and the Caribbean (ECLAC) and the UN Economic Commission for Europe (UNECE).

Only recently, the literature has paid growing attention to the (re) emergence of the 'region' as a unit to mitigate the negative effects of market instability derived from globalization (Telò, 2001; Beeson, 2007), and as development space for managing uncertainties through social regulation (Yeates and Deacon, 2006; Deacon et al., 2010; Kaasch and Stubbs, 2014). The regional arena is thus portrayed as a relevant tool in managing the negative impact of globalization on social protection (Deacon et al., 2010). The regional tier is described as enabling inter-states' agreements and consensus in the social policy field, which in turn, can lead to the reduction of social exclusion and the promotion of more inclusive societies through four main mechanisms: regional social redistribution mechanisms, regional social regulations, regional social rights, and regional intergovernmental cooperation (Deacon et al., 2010; Deacon et al., 2007; Yeates, 2014b; Yeates and Deacon, 2006). The European Union (EU) is probably one of the most studied regional organizations. Yet, recently the literature has broadened the geographical scope to include regional processes and institutions in the developing world.

From a Latin American perspective, with the turn of the century, there has been a veritable explosion of scholarship on social policy provisions at the regional level. Analyses have empirically explored the governance of regional cooperation in issues like education (Verger and Hermo, 2010; Gomes et al., 2012; Botto, 2016; Perrotta, 2016; Larrechea and Castro, 2009), employment (Espino, 2016), health (Riggirozzi, 2012; Bianculli and Ribeiro Hoffmann, 2016a; Herrero and Tussie, 2015) and migration (Margheritis, 2013). Collectively, this work has broadened our understandings of the actors, institutions and processes underlying regional organizations' involvement in social policies beyond the EU, and its impact on regulation and development.

Still, when it comes to the factors that have triggered such regional developments, much of these studies have underscored the political shift to the left or pink tide. Certainly, the emergence of centre-left and left-leaning governments that sought alternative political, 
economic, and development policies at the domestic level also resonated at the regional level where cooperation enabled the articulation of social policy regionalism. These agendas have consequently set new contours for regionalism in Latin America, especially when compared with the predominant free trade paradigm during the 1990s. However, within this more general trend marked by the return of the state, of politics, and of social concerns, differences persist in the practices, institutions, and mechanisms devised to advance regional cooperation in fields such as education, health, employment, and gender.

The factors that account for such differences remain largely unexplored. Moreover, regional social policies and regulations have largely escaped comparative scrutiny. Relevant exceptions include the first comparative study of social policy regionalism in Africa, Asia, Europe and Latin America by Deacon et al. (2010) and the works by Riggirozzi and Yeates (2015) and Amaya et al. (2015), who have explored the regional dimension of health policy across organizations in Southern Africa and South America. More specifically, this last study offers an analysis of the framing of health in foreign policy at the regional level in different regional organizations.

This paper aims to contribute to this body of work by proposing an analytical framework to comparatively assess regulatory developments across policy areas. Exploring this issue is timely and relevant. First, globalization and regionalism have altered the debate about social policy, and also the nature of the challenges and problems themselves. Secondly, regional integration in Latin America has been traditionally asymmetric. Countries have largely pursued cooperation through 'negative regulation', but this has not been matched by 'positive regulation' (Holman, 2004). There is an agreement that whereas it might be relatively easy for governments to 'deconstruct' or remove obstacles to a free or common market goal, positive cooperation is much more ambitious and complex as it aims at a joint constructive action. Yet, the notion of social policy, often referred to as measure of positive integration, may itself conceal relevant variations regarding how policy problems are defined across subpolicy fields. In other words, much variation could emerge not only across policy areas, i.e. social and environmental policy; but also across sub-policy fields, i.e. health and education as part of a broader social policy agenda. Thus, it is necessary to move beyond 'the functional titles that are usually used to describe policy' and which may be 'inadequate for effective analysis' (Peters, 2005: 351).

Against this broader backdrop, the main goal of this paper is to provide a better understanding of the nature and specific characteristics of regional policy problems, which is expected to yield richer insights into the forms in which social policies and regulations are 
implemented at the regional level, irrespective of the wider regional institutional context, on the one hand, and the more general functional denomination, on the other.

\section{How to explain regional social policies and regulations}

This paper relies on a comparative public policy approach. Hence, it incorporates insights from the field of public policy and administration that are fundamental to fully understand the increased multidimensional characteristics of contemporary public policy (Peters, 2015b) and decision making processes, which more and more operate above and beyond the state (see interalia Stone and Ladi, 2015). More specifically, I propose an analytical framework in reference to the policy problems approach that relates the definition of policy problems to the institutions and the specific instruments created to address them. Such an approach is crucial to assess how the problem is dealt with, who the participants will be, how decision makers will process them, and how regional organizations will intervene.

The analysis advances in three steps. First, I begin with the analysis of how the policy problem is defined. A policy problem 'can be viewed as a disconnection between a desired state and the current state of affairs' (Hoornbeek and Peters, 2017: 369). Thus, examining problem definition involves ascertaining how 'society and/or its political system define and frame particular disconnections between current conditions and desired states as appropriate for pursuit of resolutions by government' (Idem). The first question this paper addresses then is what the problem is about; i.e. is it a problem of development? Is it a problem of market creation? It is a problem of regional citizenship? While certainly a difficult task, answering this first question is crucial for the type of institutional response and the final outcome of the process (Peters, 2005). In a second step, the analysis assesses which institutions are established or charged with the responsibility of dealing with the policy problem as defined in the previous stage. Finally, I look into how these institutions deal with and process these problems as they attempt to correct the real and/or perceived defect in society or economy (Peters, 2005: 354). The notion of institutions refers to the decisionmaking mechanisms and arrangements created by regional organizations or charged with the responsibility of dealing with the policy problem, whereas the number and type of policy instruments adopted and which are 'brought into existence, constructed or composed' (Kassim and Le Galès, 2010: 4) are the tools for implementation and translating the policy problems into effective action (Peters, 2015b: 101). 
The original research for this piece follows a qualitative and inductive approach to analyse and comparatively assess regional policy developments in education and health and draws on multiple sources. First, I carried out secondary analysis based on a review of published academic and policy studies on education and health cooperation. Secondly, I combined these with publicly available documents issued by MERCOSUR and other relevant policy institutions in these two policy sectors. More specifically, I constructed a database collecting decisions and resolutions passed by MERCOSUR in education and health during the last 25 years (1991-2016). Whereas the analysis on the policy problem definition and the institutional mechanisms relies on the foundational documents, ii including the Asunción Treaty and the Ouro Preto Protocol, and those establishing the institutions responsible for education and health regulations, together with the specific programs, the analysis of the policy instruments is based on the dataset, which comprises Decisions by the Common Market Council (CMC) and Resolutions by the Common Market Group (CMG). ${ }^{\text {iii }}$ NVivo 11 qualitative software was used to assist the coding and analysis of these documents according to their content. The qualitative coding of the documents was mainly inductive, whereby several readings of the documents led to the identification of key themes that were then coded and comparatively analysed across policy areas.

\section{MERCOSUR: From free trade to social policies and regulations?}

Regional cooperation pervades the history of Latin America. Calls for political unity could be heard during the wars for independence in the late eighteenth and early nineteenth centuries. Yet, starting in the 1960s, economic integration, rather than political cooperation, was the main objective of the first or old wave of regionalism, devised as a functional complement to import substituting industrialization. Since then, two other waves of cooperation have followed. By the early 1990s, the 'open' and 'new' regionalism supported an openness to global capitalism (Grugel, 2004), the transnationalization of trade and production and the progressive liberalization of markets in developing countries (Hettne, 1999). With the end of the Cold War and as Latin America underwent political and economic liberalization, new regional organizations were then constructed and old ones reconstructed and reframed as countries pursued a multitier strategy of trade liberalization, encompassing the regional, the inter-regional, and the multilateral arenas (Bianculli, 2017).Finally, with the turn of the century, regional initiatives brought to the fore the importance of discussing regional cooperation in other terms. Moving beyond the exclusive focus on trade 
liberalization, regional arrangements have been organised to manage investments, infrastructure, security, development and social policy.

MERCOSUR became the stellar example of the new regionalism era of the 1990s. The Treaty of Asunción (1991) created MERCOSUR to establish a common market and promote trade flows among the four-member states, i.e. Argentina, Brazil, Paraguay and Uruguay. ${ }^{\text {iv }}$

In 1994, the four members of MERCOSUR subscribed the Ouro Preto Protocol, which established its institutional structure, which is fully intergovernmental, with the ministers of economy and foreign affairs being the main actors. Two are the main decision bodies. First, the CMC, the highest decision-making power within MERCOSUR, is responsible for setting the political strategies of the bloc and the promotion and constitution of the common market. Composed of the ministers of Foreign Affairs and of Economy, the CMC meets as often as it deems appropriate, and must do so at least once every six months with the participation of the Presidents of member states. Secondly, the GMC constitutes the executive body of MERCOSUR and brings together five regular members and five alternate members per country, who are designated by the respective member states. These delegations must include representatives of the ministries of Foreign Affairs, Economy (or equivalent) and Central Banks. The GMC is also responsible for negotiations with third parties, and its structure includes Groups, Working Subgroups, Ad Hoc Groups and Specialized Meetings. Whereas the results of the work of the CMC are decisions, the CMG acts by means of resolutions. Both types of norms are mandatory and must be transposed to the national level by member states.

From a policy perspective, the bloc made some early moves towards promoting regional social policies and regulations already in the 1990s. Specific steps were taken in education and health. Thus, to the extent that these social issues have been on MERCOSUR agenda since almost its inception, the bloc offers an interesting case for exploring social policy regionalism.

\section{Education and health policies and regulations under MERCOSUR}

\section{Defining the policy problem}

The foundational treaties of MERCOSUR do not refer to education and health. Yet, the Asunción Treaty, which sets the basis of the new regional bloc, does underscore the broadening of domestic markets through integration as a key condition for accelerating 
economic development with social justice. In a rather similar vein, it also acknowledges the need to promote scientific and technological development in member states and to modernize their economies to diversify the offer and quality of their products and services in order to improve the living conditions of their populations. This did not translate into concrete policies or strategies. Nonetheless, in 1991, member states placed education and health on the bloc's agenda, though policy problems in these subsectors were labeled differently. Between 1991 and 2016, ten documents are identified as the most important in the area of education for MERCOSUR. Education is presented as a policy problem of regional scope. In so doing, they characterize education as a problem of development, but also as a problem of regional integration and regional identity. These documents acknowledge a relevant gap between the observed and perceived situation of these countries and the region in terms of development and social justice. Thus, already in December 1991, the Ministers of Education signed a Protocol of Intentions, where education as a policy problem is linked to the acceleration of the processes of economic development with social justice (MERCOSUR, 1991b). While acknowledging the role of education as a 'generator and transmitter of values, scientific and technological knowledge, in addition to its formative and productive purposes', this document underscores that raising levels of education and comprehensive training are crucial steps to accelerate the modernization process of member states. These same policy problem definitions reverberated in the vision statement of the Meeting of MERCOSUR Education Ministers (RME), where education is characterized as being an essential factor 'to achieve prosperity, progress, well-being and social justice' (MERCOSUR, 1991a). With the turn of the century, education as a policy problem is also defined in terms of poverty eradication, fighting inequalities, and social and economic mobility (MERCOSUR, 2001a). Education is discussed as being crucial to development with social justice and inclusion (MERCOSUR, 2006). Moreover, education is committed to social development and the attention of the most vulnerable social sectors (MERCOSUR, 2011).

Regional integration and regional identity also permeate the definition of education as a regional policy problem in several documents. In this respect, the Ministers of Education of the four original member states underscored the relevant role of education for the regional integration process to consolidate and project (MERCOSUR, 1991b). Education as a policy problem is also defined as a fundamental pillar of the integration process in later documents (MERCOSUR, 1992a; MERCOSUR, 1997; MERCOSUR, 1991a). Furthermore, raising educational and training levels is deemed crucial 'to assure its irreversibility' (MERCOSUR, 2006), and to strengthening the regional integration project (MERCOSUR, 2011). 
MERCOSUR goes even further as to define and discuss education as a problem of regional identity. Education entails a space for the formation of a regional identity and reaffirming it in the face of the ever more complex challenges of the contemporary world (MERCOSUR, 2001a; MERCOSUR, 2011; MERCOSUR, 1991b). Various elements underlay the idea of education as a problem of regional identity, including the promotion of citizen's awareness of the integration process and a culture of integration, all of which is to advance through reciprocal knowledge, interculturality and respect for diversity (MERCOSUR, 2001a; MERCOSUR, 1998a). In all, education through human resources training quality and access to knowledge constitutes an essential tool to develop a regional citizenship.

Health was also an early policy concern of MERCOSUR. Along these 25 years, seven documents are identified as the most relevant in defining health as a policy problem of regional scope. These documents evidence that health is more strongly defined in terms of developing the regional project and in close relation to policy harmonization, taken as the elimination of contradictory or conflicting national regulations and norms. Already in 1991, the Asunción Treaty (Annex V) established various working subgroups, many of which had implications for health, as in the case of transport, industrial and technological policies, and agriculture and technical norms. Especially, this last subgroup generated activities and debates in health as early as 1991. One year later, health became part of the Working Subgroup 3 (WSG 3) on Technical Norms(MERCOSUR, 1992b). This document, however, did not provide a clear definition of health as a policy problem. Yet, in practice, this body had a clear technical and harmonization approach to health as shown by the content of the more than 50 norms that were passed between 1992 and 1996.

In 1995, this implicit definition of health as a technical problem connected to the idea of harmonization and market creation through the abolishment of technical obstacles, was complemented with a political approach. Given the perceived situation regarding the regional project, which was in its infant years, and the need to guarantee further progress in the integration process, health was defined as a policy problem to be tackled at the regional level (MERCOSUR, 1995). Moreover, health was characterized as a political problem, of ministerial responsibility and that required policy coordination in the field of health at MERCOSUR level.

Only one year later, the technical approach to health was explicitly recognized and thus further strengthened: health is categorized as a problem of policy harmonization (MERCOSUR, 1996). More specifically, health as a policy problem is specified as a commitment to the harmonization of health rules, and thus directly related to the 
strengthening and deepening of the regional integration project. Such a definition has remained virtually unchanged along the years. In all instances, the definition of health policy as a catalyst of the regional integration project presents health as policy problem central to the harmonization of sectoral policies between MERCOSUR member states. In so doing, harmonization becomes closely intertwined with the elimination of all technical obstacles to intra-regional trade flows. These definitions pervade all regional negotiating mandates in the area of health (MERCOSUR, 1998b; MERCOSUR, 2001b; MERCOSUR, 2005; MERCOSUR, 2007; MERCOSUR, 2014). The technical dimension becomes more apparent in the last negotiating mandate that introduces a new refined nuance by referring to the need to identify, evaluate and overcome existing asymmetries in order to accelerate the integration process (MERCOSUR, 2014).

In all, when comparatively assessed education and health policy evidence relevant differences in terms of the policy problem definition underlying the MERCOSUR agenda. The main policy problem articulated in education related to social and economic development, with social justice and wellbeing, the consolidation of the regional integration process and the creation of a regional identity. This contrasts sharply with the definition of health, where the notions of development and regional identity remain absent. Health is also defined as a problem of developing and strengthening the regional project, but in this case, it stands in close relation to the notion of technical harmonization between partners. In sum, there is hence a relevant association between education and the regional project, including the promotion of regional cooperation and a regional identity, on the one hand, and between health and harmonization, including the eliminations of obstacles to trade flows, on the other.

\section{Setting the institutional mechanisms}

We now turn to the particular institutional arrangements charged with the responsibility of addressing the policy problem MERCOSUR attempted to tackle at the regional level.

From the perspective of education, mainly defined as a question of development, regional identity and regional cooperation, different institutional mechanisms were devised. Already in 1991, the CMC explicitly underscored the policy idea that raising education levels was a crucial factor to strengthen the regional process and to achieve prosperity, progress, wellbeing and social justice in the region. This translated into the creation of the RME, and its incorporation into MERCOSUR's institutional structure. ${ }^{\mathrm{vi}}$ Building on the existing Protocol of Intentions, the RME was then granted the authority to propose the CMC, 
measures towards the coordination of education policies between member states and thus contribute to the development of MERCOSUR (MERCOSUR, 1991a). Since its creation the RME has held 'the decisive say in all matters concerning education' (Gomes et al., 2012). The RME was set as the decision-making body responsible for all education strategies and for promoting policy coordination defined as making the necessary adjustments in national policies to achieve common regional goals. Policy coordination has imbued all RME decisions, including the creation of new institutional mechanisms as in the case of the SEM. Established in 1992, the SEM constitutes a regional space ${ }^{\text {vii }}$ to promote policy coordination between member and associated states (MERCOSUR, 1992a) and thus articulate education issues with the broader process of regional integration. Moreover, the SEM is also granted the responsibility of promoting a regional identity as well as citizen's awareness of the common regional project. In fact, these responsibilities permeate all analyzed documents between 1991 and 2016, and more specifically the Strategic Plans of the SEM.

Just as MERCOSUR was relaunched in 2001, the Strategic Plans of the SEM were set. ${ }^{\text {viii }}$ The three Strategic Plans that have been passed so far underscore the creation of a common regional space through the coordination of educational policies to promote citizen awareness in favor of the regional process thus supporting integration and the construction of a regional identity and citizenship (MERCOSUR, 2001a; MERCOSUR, 2006; MERCOSUR, 2011). Another relevant task is that of designing and executing policies to promote an education of quality for all, contributing thus to MERCOSUR's objectives and supporting development. Also, in 2001, the sector was restructured, leading to several institutional changes. Regional coordination of education policies was then to be further enhanced through the Regional Coordination Committee (CCR), which created three Regional Coordinating Commissions: basic, technological, and higher education, responsible for defining the policies of their specific areas and for making proposals to the RME. Policy coordination also reached teachers' training programs when a Teacher Training Regional Coordinating Commission was established in 2011. ${ }^{\mathrm{ix}}$ Other institutional innovations included the Management Committee of the Information and Communication System (CGSIC) and the Projects Management Groups (GGP). Whereas the CGSIC was to support policy coordination through knowledge dissemination, information exchange and the use of social communications technologies, the GGP was to develop all projects approved within the SEM. Finally, since 2004 the SEM has operated the Education Fund of MERCOSUR, a specific regional fund to support regional coordination projects and programs Ruled by an 
Advisory Committee since 2005, this fund only became operational in 2010 as Brazil made effective its contribution (Botto, 2016).

The institutional mechanisms devised in the area of health were mainly charged with the responsibility of promoting policy harmonization, developing the integration process, and health as a regional public good. Policy harmonization pervaded the provisional institutional structure laid down in the Asunción Treaty, which included the creation of different working subgroups of technical level to support the GMC in the coordination of macroeconomic and sectoral policies in their respective areas of competence. Health became the focus of the commission 'Health Products' created within the Working Subgroup 3 (WSG 3) on 'Technical Norms' (MERCOSUR, 1992b). Its objective was to discuss the harmonization of sanitary norms to abolish technical obstacles and allow the free movement of food and health products (Sánchez, 2007; Acosta et al., 2007). More specifically, the WSG 3 dealt with pharmaceuticals and blood products, cosmetics and disinfectants (Guimaraes Queiroz and Giovanella, 2011: 184). Between 1992 and 1996, the commission on Health Products elaborated more than 50rules and regulations that were then passed as resolutions by the CMG.

Adding to this technical institutionalization of health and building on the Ouro Preto Protocol that included the creation of specialized sectoral meetings at the ministerial level, the RMS was established in 1995. The RMS brings together national health ministers, associated members as observers and representatives of the Pan American Health Organization (PAHO) as technical-advisory body. As such, the RMS stands as the hierarchically superior political instance responsible for policy coordination and for supporting joint actions to promote, prevent, and protect health (MERCOSUR, 1995). These actions are carried out in each country using resources from their own health systems. Additionally, the RMS relies on the work of 11 Intergovernmental Commissions responsible for proposing policy coordination strategies in several areas, i.e. medicines policy, sexual and reproductive health, HIV-AIDS, and non-communicable diseases, among others. These commissions include national experts and technicians, who present and debate themes in the light of national policies and thus propose agreements, programs, strategies and guidelines. The work of these commissions adds to the different subgroups known as Focal Points (Núcleos de Articulación) that deal with specific issues: 1. Health Information and Communication Systems, 2. Border Health; 3. Medical Care and Rational Use of Technology, and 4. International Cooperation in Health. Finally, in 2008, and based on the idea that information sharing and dissemination is fundamental to support and contribute to the 
development and further strengthening of regional policy coordination, the RMS agreed on the creation of the MERCOSUR Observatory of Health Systems (OMSS) to produce, disseminate and share knowledge about member states' health systems, including social determinants of health, models of care, financing and management. ${ }^{x}$

Yet, the volume and relevance of the rules and regulations promoted by the commission on Health Products under WSG 3 showed that health policy harmonization was crucial to eliminate all obstacles and technical barriers to trade and further strengthen the creation of the regional market. Building on this, the CMG approved the creation of the Working Subgroup No 11 (WSG 11) 'Health' already in 1996 (MERCOSUR, 1996). This comprises specialists and technical experts from the national ministries and other related public bodies. It is thus set as a technical body of deliberative character responsible for all policy issues relating to the harmonization of national legislation and technical standards, while also establishing specialized commissions to deal with the elaboration and implementation of negotiation mandates in three main areas: Health Products, Health Care Services and Health Surveillance. When analyzing the five negotiation mandates passed between 1998 and 2014, it becomes clear that the main responsibility is that of pursuing the harmonization of technical norms and standards (MERCOSUR, 2001b; MERCOSUR, 2014; MERCOSUR, 2005; MERCOSUR, 1998b; MERCOSUR, 2007). Whereas other tasks also mentioned in the analyzed documents refer to health promotion and protection, these are more strongly related to the dismantling of existing obstacles to regional trade to promote the integration process.

Both education and health show relatively complex institutional structures. Yet, differences emerge regarding the main responsibilities attached to them. Policy coordination is the main responsibility of the institutional mechanisms set for education, including the RME but also of the various institutional arrangements established thereafter. Health, on the contrary, relies on a division of labor between the RMS a more political body, and WSG 11 that works as a deliberative and technical mechanism. Nevertheless, when looking across the relevant documents, policy harmonization and the elimination of technical obstacles to trade and market creation is a more central responsibility that goes hand in hand with the promotion of the regional project. In the case of education, policy coordination is paralleled with the task of promoting education as a regional public good and of supporting economic and social development. Is the variation in the responsibilities attached to the regional institutional mechanisms reflected in the regional regulatory output? 


\section{The policy instruments and strategies}

When analyzing the decisions and resolutions established in the area of education and health between 1 January 1991 and 31 December 2016, the 51 norms passed in the field of education contrast to the 300 norms passed in the area of health (Graph 1). Relevant differences also become apparent when looking more deeply into the type of norm and the specific institutional mechanism responsible for promoting the new norm (Graph 2).

\section{Graph 1: Type of norm in education and health regulation}

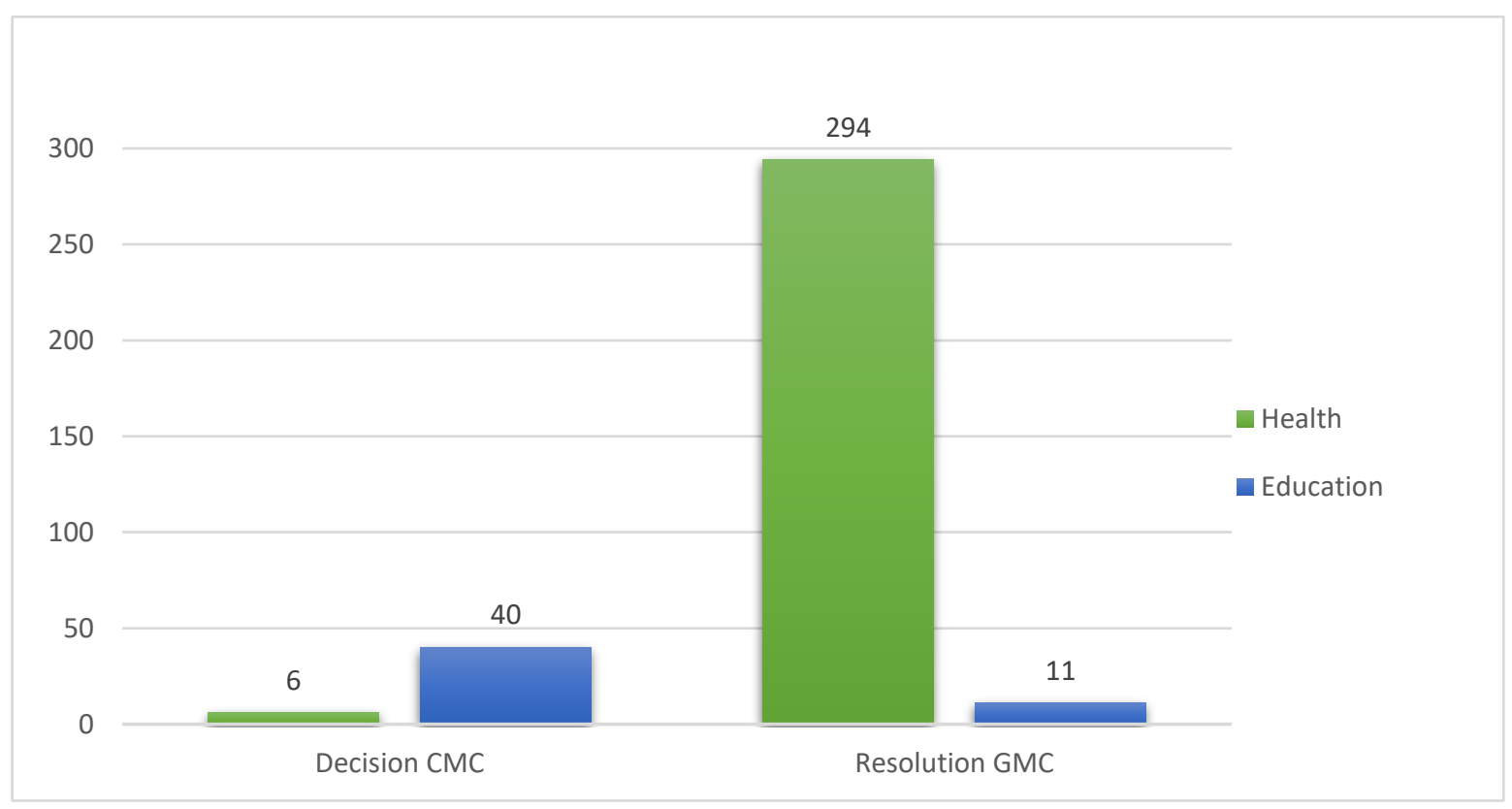

Source: Own compilation based on MERCOSUR 'Regulations and Official Documents'

Regulations and policies in education correspond more strongly with Decisions from MERCOSUR's highest political decision-making body, the CMC. This matches with the definition of education as a problem of economic and social development, of strengthening the regional project and promoting a regional identity. In line with this, the institutional mechanisms that were charged with the responsibility of addressing regional education have more strongly emphasized the provision of education as a regional good, based on policy coordination between member states. This has resulted in a larger number of political decisions, which also mainly stemmed from the initiative of the RME.

Regional health regulations have been mainly of a technical character. Health has been mainly regulated through Resolutions by the executive body of MERCOSUR, the CMG, which is 
responsible for the creation of the regional market. This confirms the more technical nature of the policy definition underlying regional regulation in health. Moreover, the main body providing regulatory input has been the WSG 11, which as a technical body under the axis of the CMG is very much focused on health regulatory harmonization. In all, the definition of health as a problem of policy harmonization has more strongly triggered efforts to bring into line the rules for the free circulation of health products and other policy issues related to the market creation as a way towards the strengthening of the regional project, mainly the common market objective. Whereas the RMS addresses health policy coordination and health promotion, the fact that only 3 rules have stemmed from this body shows the extent to which policy harmonization has prevailed over policy coordination.

\section{Graph 2: Main bodies of origin of education and health regulations}

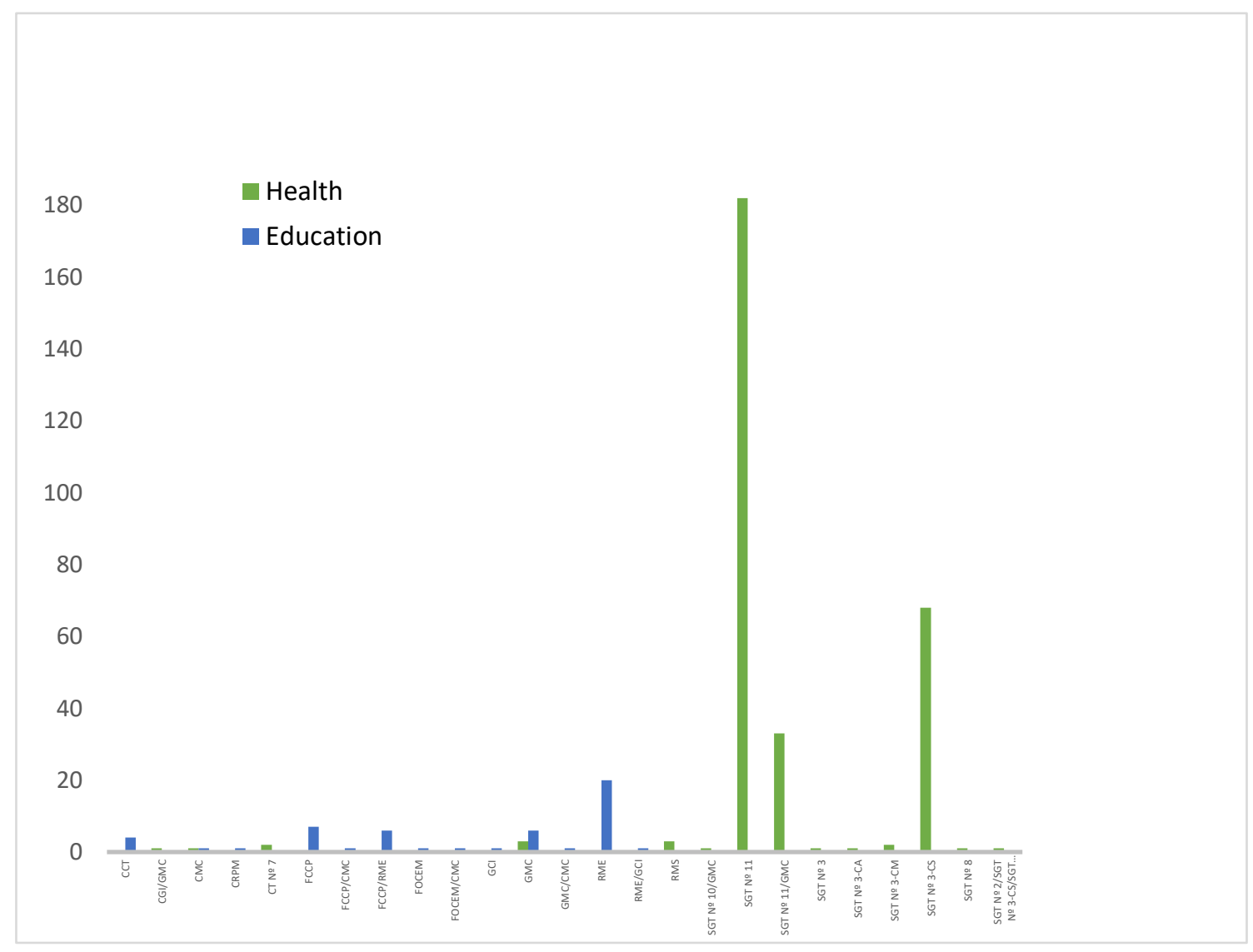

Source: Own compilation based on MERCOSUR 'Regulations and Official Documents'

\section{Some comparative insights and further avenues for research}

This paper has looked into the variation in the ways in which social policies and regulations advance at the regional level. Based on the empirical analysis, relevant differences emerge 
when looking across MERCOSUR policies and regulations in education and health from 1991 to 2016. This variation seems attributable to the specific way in which education and health were defined and framed as a regional policy problem in the early years of MERCOSUR. While relevant, explanations focused on the political color of governments may not be enough to account for such differences despite the intergovernmental character of regional organizations. Variation across education and health also confirm the need to go beyond functional denominations.

Since its creation in 1991, MERCOSUR has attempted to complement its trade and free market focus with regional regulatory cooperation in various social agendas. Education and health are two long-standing areas of regional cooperation. Yet, the underlying policy problem definition differs notably, leading in turn to different institutional mechanisms and policy instruments.

The definition of education as a problem of social development, regional integration and identity has led to strong policy coordination to achieve common regional goals and promote education as a regional public good. Policy coordination in education lies almost exclusively in the hands of the RME and thus, more directly relates to the decisions passed through the $\mathrm{CMC}$, the highest political decision-making body in the bloc. As a result, the RME has had the decisive say on all issues related to education and has developed a dense institutional structure to deal with this policy agenda. Health, on the contrary, evidences two different policy problem definitions: health as problem of policy harmonization and closely connected to the development of the integration process, mainly through the reduction of barriers and obstacles, on the one hand, and health as problem of policy coordination aimed at providing a regional public good, on the other. This has resulted in two different institutional mechanisms: the WSG 11 and the RMS 11, of a technical and political nature respectively. In practice, however, even if the RMS is also related to the CMC and has promoted a number of committees, commission and groups to handle the health agenda, regional policy making seems to rely more heavily on the GMC through the WSG 11, also leading to more regulatory density, i.e. the number of regulations and rules passed during the last 25 years, in this policy field. Also of interest is the creation of a regional fund to support coordination policies and activities in education, while such a regional mechanism is absent in the health area.

Building on this, it may be argued that the definition of regional policy problems affects the institutional mechanisms and policy strategies devised to address them. Yet, as with any conceptual model, this analytical framework also has its limitations. First, the framework may promote a rather objectivist characterization of policy problems. Yet, I remain cognizant that 
these are the result of a political process of definition and framing involving different constellations of actors and strategies. This latter perspective may be part of future research to broaden our understanding of regional policy problems. Secondly, the analysis has mainly focused on the formal de jure rules. While recognizing the relevance of the informal dimension of regional cooperation and integration, I think that assessing and understanding formal procedures and rules are relevant given that informality mainly takes place in the shadow of formal provisions' (Koop and Lodge, 2017: 1318). Finally, exploring particular characteristics and attributes of policy problems, i.e. complexity, salience or interdependence, may also reveal further insights.

This paper has provided a comparative policy approach to assess regional regulatory regulations and policies. The analysis appears to produce at least some potentially useful insights about the beyond-the-nation state, regional dynamics of policy coordination and regulation in new realms of public policy activity. The variation observed across regional regulations in education and health is relevant given that both policy areas are part of the social agenda or social dimension of regionalism and despite the wider institutional context marked by the intergovernmental character of decision-making in MERCOSUR. This speaks to the diversity and complexity of regional regulatory processes and the need for more nuanced analysis to further develop our understanding of the variations, not only across regional organizations but also across policy areas. This first exploratory study aims to contribute to this debate. 


\section{References}

Acosta C, Giovanella L, Heimann LS, et al. (2007) Una agenda de investigaciones en sistemas y servicios de salud en el contexto de la integración regional: informe del Foro MERCOSUR sobre Integración Regional y Sistemas de Salud. Cadernos de Saúde Pública 23: 315-321.

Amaya AB, Rollet V and Kingah S. (2015) What's in a word? The framing of health at the regional level: ASEAN, EU, SADC and UNASUR. Global Social Policy 15: 229-260.

Beeson M. (2007) Regionalism and Globalization in East Asia: Politics, Security and Economic Development, Basingstoke: Palgrave.

Bianculli AC. (2016a) Latin America. In: Börzel TA and Risse T (eds) The Oxford Handbook of Comparative Regionalism. Oxford: Oxford University Press, 154-177.

Bianculli AC. (2016b) Regulatory governance regimes and interregionalism: exploring the dynamics of EU-Mercosur negotiations. Canadian Journal of Latin American and Caribbean Studies / Revue canadienne des études latino-américaines et caraïbes 41: 1-24.

Bianculli AC. (2017) Negotiating Trade Liberalization in Argentina and Chile: When Trade Policy Creates Domestic Politics, New York and Abingdon: Routledge.

Bianculli AC and Ribeiro Hoffmann A. (2016a) Regional Integration and Health Policies: Regulatory Governance Challenges in MERCOSUR. In: Bianculli AC and Ribeiro Hoffmann A (eds) Regional Organizations and Social Policy in Europe and Latin America. A Space for Social Citizenship? Basingstoke: Palgrave Macmillan, 251-270.

Bianculli AC and Ribeiro Hoffmann A. (2016b) Regional Organizations and Social Policy in Europe and Latin America: A Space for Social Citizenship? Basingstoke: Palgrave Macmillan.

Botto M. (2016) Policy diffusion and higher education reforms: Between market and state regulation - Where does Mercosur stand? In: Bianculli AC and Ribeiro Hoffmann A (eds) Regional Organizations and Social Policy in Europe and Latin America. A Space for Social Citizenship? Basingstoke: Palgrave Macmillan, 165-184.

Chou M-H and Ravinet P. (2017) Higher education regionalism in Europe and Southeast Asia: Comparing policy ideas. Policy and Society 36: 143-159.

Deacon B. (2007) Global Social Policy and Governance, London: SAGE Publications.

Deacon B, Macovei MC, Van Langehove L, et al. (2010) World-Regional Social Policy and Global Governance. New research and policy agendas in Africa, Asia, Europe and Latin America. London: Routledge.

Deacon B, Ortiz I and Zelenev S. (2007) Regional Social Policy. DESA Working Paper, 37.

Espino A. (2016) Work and employment in Mercosur from a gender perspective: Challenges and public policies. In: Bianculli AC and Ribeiro Hoffmann A (eds) Regional Organizations and Social Policy in Europe and Latin America. A Space for Social Citizenship? Basingstoke: Palgrave Macmillan, 139-161.

Fraga D. (2001) Procesamiento de Normas en el MERCOSUR. El caso : SALUD. Montevideo: Secretaría Administrativa del MERCOSUR.

Fulquet G. (2005) El Proyecto Educativo para el MERCOSUR y los Debates en torno a la Internacionalización de la Educación Superior, Buenos Aires: Centro Argentino de Estudios Internacionales (CAEI).

Gomes AM, Robertson SL and Dale R. (2012) The social condition of higher education: globalisation and (beyond) regionalisation in Latin America. Globalisation, Societies and Education 10: 221245.

Grugel J. (2004) New Regionalism and Modes of Governance - Comparing US and EU Strategies in Latin America. European Journal of International Relations 10: 603-626. 
Guimaraes Queiroz L and Giovanella L. (2011) Agenda regional da saúde no Mercosul: arquitetura e temas. Revista Panamericana de Salud Publica 30: 182-188.

Hermo JP. (2003) El Sistema Argentino en el marco del MERCOSUR. In: Pugliese JC (ed) Politicas de Estado para la Universidad Argentina. Balance de una gestión en el nuevo contexto nacional e internacional. Buenos Aires: Secretaría de Políticas Universitarias, Ministerio de Educación, Ciencia y Tecnología.

Herrero MB and Tussie D. (2015) UNASUR Health: A quiet revolution in health diplomacy in South America. Global Social Policy 15: 261-277.

Hettne B. (1999) Globalization and the new regionalism: The second great transformation. In: Hettne B, Inotai A and Sunkel O (eds) Globalism and the new regionalism. London: Macmillan, 1-24.

Holman O. (2004) Asymmetrical regulation and multidimensional governance in the European Union. 11: $714-735$.

Hoornbeek JA and Peters BG. (2017) Understanding policy problems: a refinement of past work. Policy and Society 36: 365-384.

Kaasch A and Stubbs P. (2014) Transformations in Global and Regional Social Policies. Houndsmills Basingstoke: Palgrave MacMillan.

Kassim H and Le Galès P. (2010) Exploring Governance in a Multi-Level Polity: A Policy Instruments Approach. West European Politics 33: 1-21.

Kennett P. (2013) A Handbook of Comparative Social Policy. Cheltenham, UK: Edward Elgar Publishing.

Koop C and Lodge M. (2017) What is regulation? An interdisciplinary concept analysis. Regulation \& Governance 11: 95-108.

Larrechea EM and Castro AC. (2009) New Demands and Policies on Higher Education in the Mercosur: A Comparative Study on Challenges, Resources, and Trends. Policy Futures in Education 7: 473-485.

Margheritis A. (2013) Piecemeal regional integration in the post-neoliberal era: Negotiating migration policies within Mercosur. Review of International Political Economy 20: 541-575.

MERCOSUR. (1991a) MERCOSUR/CMC/DEC N 07/91. Reunión de Ministros de Educación. Brasilia: MERCOSUR.

MERCOSUR. (1991b) Protocolo de Intenciones. Brasilia: MERCOSUR.

MERCOSUR. (1992a) MERCOSUR/CMC/DEC N ${ }^{\circ}$ 7/92. Plan Trienal para el Sector Educación en el Contexto del MERCOSUR. Brasilia: MERCOSUR.

MERCOSUR. (1992b) MERCOSUR/GMC/RES 51/92. Comisiones en los SGT No 2, 3 y 6. Montevideo. MERCOSUR.

MERCOSUR. (1995) MERCOSUR/CMC/DEC. No 3/95. Reunión de Ministros de Salud. Asunción: MERCOSUR.

MERCOSUR. (1996) MERCOSUR/GMC/RES No 151/96. Creación del Subgrupo de Trabajo N ${ }^{\circ}$ 11 'Salud'. Fortaleza: MERCOSUR.

MERCOSUR. (1997) MERCOSUR/CMC/DEC No 25/97. Prórroga de la vigencia del 'Plan Trienal para el Sector Educación en el Contexto del MERCOSUR. Montevideo: MERCOSUR.

MERCOSUR. (1998a) MERCOSUR/CMC/DEC No 13/98. Plan Trienal y Metas del Sector Educacional. Rio de Janeiro: MERCOSUR.

MERCOSUR. (1998b) MERCOSUR/GMC/RES. No 4/98. Pauta Negociadora del SGT No 11. Buenos Aires: MERCOSUR. 
MERCOSUR. (2001a) MERCOSUR/CMC/DEC. N 15/01. Estructura orgánica y plan de acción 2001-2005 del Sector Educativo del MERCOSUR, Bolivia y Chile. Montevideo: MERCOSUR.

MERCOSUR. (2001b) MERCOSUR/GMC/RES. No 21/01. Pauta Negociadora del SGT No 11 'Salud'. Asunción: MERCOSUR.

MERCOSUR. (2005) MERCOSUR/GMC/RES No 06/05. Pauta negociadora del SGT No 11 'Salud'. Asunción: MERCOSUR.

MERCOSUR. (2006) Plan del Sector Educativo del MERCOSUR 2006-2010. MERCOSUR.

MERCOSUR. (2007) MERCOSUR/GMC/RES. No 13/07. Pauta Negociadora del SGT No 11 'Salud'. Asunción: MERCOSUR.

MERCOSUR. (2011) Plan del Sector Educativo del MERCOSUR 2011-2015. Montevideo: MERCOSUR.

MERCOSUR. (2014) MERCOSUR/XCIV GMC/ DT No 17/14. Pauta Negociadora del SGT N ${ }^{\circ}$ 11 'Salud'. Caracas: MERCOSUR.

Mittelman JH. (2000) The Globalization Syndrome: Transformation and Resistance, Princeton, NJ: Princeton University Press.

Perrotta D. (2016) Mercosur's regional policies in higher education: The diffusion of accreditation and quality assurance policies. In: Bianculli AC and Ribeiro Hoffmann A (eds) Regional Organizations and Social Policy in Europe and Latin America. A Space for Social Citizenship? Basingstoke: Palgrave Macmillan, 185-205.

Peters BG. (2015a) Advanced Introduction to Public Policy, Cheltenham: Edward Elgar.

Peters BG. (2015b) Pursuing horizontal management: The politics of public sector coordination, Kansas, KS: University Press of Kansas.

Peters BG and Hoornbeek JA. (2005) The problem of pol2005icy problems. In: Eliadis P, Hill MM and Howlett MP (eds) Designing government: From instrument choice to governance Montreal: McGillQueens University Press, 77-105.

Peters GB. (2005) The Problem of Policy Problems. Journal of Comparative Policy Analysis: Research and Practice 7: 349-370

Riggirozzi MP. (2012) Region, Regionness and Regionalism in Latin America: Towards a New Synthesis. New Political Economy 17: 421-443.

Riggirozzi P and Yeates N. (2015) Locating regional health policy: Institutions, politics, and practices. Global Social Policy 15: 212-228.

Sánchez DM. (2007) Procesos de integración en salud: una reflexión sobre los desafíos del MERCOSUR en salud. Cadernos de Saúde Pública 23: 155-163.

Scharpf FW. (1999) Negative and Positive Integration in the Political Economy of European Welfare States. In: Marks G, Schulz M, Schmitter PC, et al. (eds) Governance in the European Union. London: SAGE, 15-39.

Stone D and Ladi S. (2015) Global Public Policy and Transnational Administration. Public Administration 93: 839-855.

Surender R and Walker R. (2013) Social Policy in a Developing World. Cheltenham, UK: Edward Elgar Publishing.

Telò M. (2001) European Union and New Regionalism. Regional Actors and Global Governance in a Post-Hegemonic Era. The International Political Economy of New Regionalisms Series. Aldershot: Ashgate Publishing Limited, xviii +330 . 
Verger A and Hermo JP. (2010) The governance of higher education regionalisation: comparative analysis of the Bologna Process and MERCOSUR-Educativo. Globalisation, Societies and Education 8: 105 -120.

Yeates N. (2014a) The idea of global social policy. In: Yeates N (ed) Understanding Global Social Policy. $1-18$.

Yeates N. (2014b) The Socialization of Regionalism and the Regionalization of Social Policy. In: Kaasch A and Stubbs P (eds) Transformations in Global and Regional Social Policies. Basingstoke: Palgrave Macmillan, 17-43.

Yeates N and Deacon B. (2006) Globalism, Regionalism and Social Policy: Framing the debate. UNUCRIS Occasional Papers, 0-2006/6.

${ }^{\mathrm{i}}$ The author(s) disclosed receipt of the following financial support for the research, authorship, and/or publication of this article: This research is funded through the project 'Regional Social Regulation in Latin America: A New Agenda for Development? Prospects and Challenges (SociAL-Reg)' (CSO2015-66411 -P) funded by the Spanish Ministry of Economy, Industry, and Competitiveness.

ii The 'founding documents' set the policy objectives and institutional mechanisms devised to achieve them. These involve 19 documents, including together with the founding treaties, those documents passed to establish the institutions responsible for policymaking in education and health.

iii MERCOSUR legal sources include the Treaty of Asunción, its protocols, related instruments, the agreements reached in the context of the Treaty of Asunción, and the Decisions by the CMC, Resolutions by the CMG and Directives by the Trade Commission as defined in the Ouro Preto Protocol (Art. 41).

"MERCOSUR includes a third decision making body: The Trade Commission, which supports the CMG and produces directives that are not mandatory for member states.

vi The RME was created building on the Asunción Treaty (Article 13), which gave the CMC the faculty to create the work program deemed necessary to ensure progress towards the establishment of the common market, including the creation of institutional mechanisms. It meets once per semester and may meet upon special request by one of the member states. Participants also include the Ministers of Education of the Associated States, who may take part in the RME meetings.

vii The SEM includes the four original founders of MERCOSUR, together with the first two associated countries: Bolivia and Chile, who participate under equal conditions as fullyfledged members (Fulquet, 2005; Hermo, 2003). Lately, also Ecuador, Colombia, Peru, and Venezuela, together with Surinam are participating of the meetings of the SEM.

viii This new policy instrument replaced the Triennial Plans that established the work plan of the SEM between 1992 and 2000.

ix This new coordinating commission resulted from and was supported by the 'Support Program for the MERCOSUR Educational Sector' (PASEM), which is co-funded by the EU and MERCOSUR as part of the interregional negotiation process (Bianculli, 2016b).

${ }^{x}$ The OMSS builds on the experience of the European Observatory on Health Systems and Policies and is financed by MERCOSUR member states and the Spanish Agency for International Development Cooperation (AECID). 